\title{
Idosos e mulheres imigrantes à margem: o caso das badanti na Itália*
}

\author{
Antonella Marcucci de Vincenti ${ }^{1}$ \\ Université Paris 13, Villetaneus (Paris, França)
}

\begin{abstract}
Na Itália, há alguns anos, uma nova profissão nasceu como resposta adaptativa ao envelhecimento da população: a das badanti. Esse termo popular designa as mulheres imigrantes trabalhadoras no domicílio de pessoas idosas. Esse fenômeno de sociedade diz respeito a quatro milhões de pessoas, contando os assistidos e as trabalhadoras. Essas pessoas se encontram à margem da sociedade e são desconsideradas. A desqualificação é implícita, inscrita na própria denominação. Badanti vem do verbo "badare", que significa "vigiar de perto", "guardar": a empatia inscrita no termo "care" ou "ajuda" não está presente. Esse welfare feito em casa, que se revelou um recurso diante da carência de serviços públicos, fez explodir as numerosas contradições que constituirão o objeto de nossa análise. A crônica dos jornais diários sobre incidentes fez vir à tona delitos, abandonos e litígios no momento de heranças, e também contradições nos grupos intermediários. O sindicato, por exemplo, é levado a gerir as guerras entre pobres: as badanti e os idosos aposentados. Todavia, a contradição mais saliente se encontra no cerne da atividade. A profissão apresenta várias facetas e, ao lado da identificação da badante com o assistido, encontramos a humilhação e o ressentimento que resultam das condições de exercício da atividade: a "domesticidade" e a "servidão".
\end{abstract}

Palavras-chave: Badanti, Velho, Idoso, Aposentado, Condição de domesticidade, Servidão, Distância necessária, Humilhação, Ressentimento.

Vieux et femmes immigrees en marge: le cas des "badanti" en Italie

En Italie, depuis quelques années, un nouveau métier est né en tant que réponse adaptative au vieillissement de la population: celui des "badanti". Ce terme populaire désigne les femmes immigrées travaillant au domicile des personnes âgées. Ce phénomène de société concerne quatre millions de personnes, en comptant les assistés et les travailleuses. Ces personnes se trouvent en marge de la société et sont déconsidérées. La disqualification est implicite, inscrite dans la dénomination même. "Badanti" vient du verbe "badare", qui signifie "surveiller de près", "garder": l'empathie inscrite dans le terme "care" ou "aide" n'est pas présente. Ce "welfare" fait maison, qui s'est révélé une ressource face à la carence de services publics, a fait exploser les nombreuses contradictions qui feront l'objet de notre analyse. La chronique des faits divers a fait émerger des délits, des abandons, des litiges lors des successions et aussi des contradictions dans les corps intermédiaires. Par exemple, le syndicat, est amené à gérer des guerres entre pauvres: les "badanti" et les vieux retraités. Toutefois, la contradiction la plus saillante se trouve au cœur de l'activité. Le métier présente plusieurs facettes et à coté de l'identification de la "badante" avec l'assisté, nous trouvons l'humiliation et le ressentiment qui résultent des conditions d'exercice de l'activité: la "domesticité" et la "servitude".

Mots-clés: Badanti, Vieux, Retraité, Condition de domesticité, Servitude, Juste distance, Humiliation, Ressentiment.

Old persons and immigrated women marginalization: the case of "badanti" in Italy

During the last years a new trade appeared in Italy as an adaptive answer to the problems arising from the ageing process of population: that of "badanti". This popular term designates the immigrated women working at old persons homes. This social phenomenon concerns four million people, including workers and assisted. These persons are marginalized and discredited. Discredit is implicit in the denomination itself. "Badanti" comes from the verb "badare" that means "to strictly survey", "to control": the empathy inscribed in the words "care" or "help" is not present. This contribution will analyze this homemade welfare, that, even if it is allowing to face the lack of public services, is disclosing several contradictions. Newspapers are reporting crimes, abandons, arguments for successions, and even contradictions inside mediation organizations. Trade unions have to manage, for example, wars between poor people: "badanti" and old-age pensioners. Anyways, the most sensible contradiction is at the core of the activity. The trade presents several faces and, besides the identification of the "badante" with the assisted person, we find the humiliation and resentment, which result from the conditions of domestic labour and servitude.

Keywords: Badanti, Old person, Pensioner, Domestic labour, Servitude, Right distance, Humiliation, Resentment.

* Publicado originalmente em: Nouvelle Revue de Psychosociologie, 15 (1), 117-130, 2013. DOI: 10.3917/nrp.015.0117

1 Antiga Mestre de Conferências da Université Paris 13, Villetaneuse. 


\section{Introdução}

$\mathrm{N}$ a Itália, nos últimos anos, num contexto de envelhecimento da população e de carência de serviços sociais, apareceram subitamente no espaço público cerca de um milhão e meio de trabalhadoras imigrantes vindas de vários lugares, mas principalmente de países do Leste. Essas mulheres estão inscritas nas listas de demanda por residência no país sob a denominação de colf (colaboradoras domésticas) e de badanti (acompanhantes de pessoas idosas e de crianças). ${ }^{2}$ Nós podemos ver essas mulheres de braço dado com pessoas idosas nas ruas das grandes ou pequenas cidades, tanto do norte como do sul da Itália. Elas também estão presentes nas zonas rurais. Sua presença, que é bastante visível e se espalha em todas as camadas sociais, nos chamou a atenção.

\section{O desafio dos empregos domésticos familiares}

Poderia parecer que, graças ao emprego de uma badante, a família italiana contemporânea é liberada de um serviço e que, dessa maneira, tenha acesso a uma condição superior, mais moderna e confortável. De fato, a crença bastante estabelecida de que os serviços e profissões ligadas aos serviços são "vis", de pouco valor, bons para os servos (aliás, a raiz do verbo servir ilustra de onde vem o nome de serviço), reside nas mentalidades sem nenhuma "atualização". Hoje, as mulheres italianas se liberam dos serviços de cuidado com as pessoas, aos quais estavam destinadas na família, descarregando-os sobre as imigrantes. A família modificou suas relações internas de troca. Todavia, talvez novamente, "tudo muda a fim de que nada mude". Não há mutações profundas, nem rupturas com o antigo sistema de "familismo" italiano (Putnam, 1993), que se ajustou ao delegar certos serviços que antes permaneciam dentro dos muros domésticos. As estatísticas mostram que a substituição das donas de casa pelas badanti é improdutiva, porque o crescimento numérico destas não corresponde ao aumento da taxa de nascimentos nem da taxa de participação das mulheres no mercado de trabalho (na Europa, a Itália detém o recorde negativo, ao lado da Espanha).

Os idosos, cada vez mais numerosos, vivem sós em suas pequenas casas ou apartamentos próprios e estão agora sob a responsabilidade dessas mulheres, vindas de outro lugar, que assumem os cuidados e lhes permitem continuar em seus domicílios. ${ }^{3}$ Novos vínculos afetivos se tecem onde o tecido social está desgastado e onde os antigos vínculos foram desfeitos (O filme Cose dell'altro mondo [Coisas de outro mundo, em tradução literal], apresentado no festival de Veneza, em 2011, ilustra bem essa temática). Consequentemente, numerosas contradições aparecem: os casamentos entre os assistidos e as badanti são cada vez mais frequentes, assim como as vinganças familiares, as rupturas, as disputas financeiras e os litígios pela herança dos assistidos, relatados nas notícias dos jornais.

Assim, o fenômeno badanti pode ser tomado como elemento revelador de duas realidades: a falta de serviços e o enfraquecimento dos vínculos intergeracionais de reciprocidade, vínculos que se tecem entre os membros da família e a comunidade adjacente.

2 Na Itália, existem em média 2.300.000 de colf e badanti, das quais 79\% são registradas junto ao l'INPS (Caixa Nacional de Seguridade e Aposentadorias). 55\% das trabalhadoras registradas denunciam irregularidades no pagamento das cotizações ( FILCAMS-CGIL, 2011). Em geral, a badante é uma mulher que entrou na Itália pelo viés de um visto de turismo. Sua idade varia entre 30 e 40 anos, é casada e tem filhos, que ficaram no país de origem, aos cuidados de outra mulher. O nível de instrução varia segundo as regiões de origem. As badanti que cuidam dos nossos avós (ou os filhos de pais que trabalham em tempo integral) são, em sua maioria, mães que sustentam financeiramente, a distância, suas famílias. Apenas 38,5\% das badanti têm uma família na Itália. A tendência a enviar dinheiro ao país de origem diminui na medida em que o projeto migratório é mais forte. Em geral, para as mulheres dos países da Europa do Leste, trata-se de um projeto de curta duração, ao passo que, entre as sul-americanas, uma em cada três planeja se instalar e começar uma nova vida na Itália (IREF, 2007).

3 O custo médio de uma vaga em uma residência para idosos, quando não há médicos, é em média três vezes o de um empregado familiar não declarado. 


\section{Interrogações}

A dimensão do fenômeno provoca um conjunto de reflexões que se relacionam com a profissão específica (se este é o caso de uma profissão) ${ }^{4}$ e o sentido que lhe é atribuído, com a evolução dos costumes da sociedade, e especialmente com a transmissão de valores de solidariedade e a construção do vínculo social.

As principais questões que procurarei elucidar são as seguintes:

- por que na Europa, principalmente na Itália e na Grécia, desenvolve-se esse serviço às pessoas, com as características marcantes da domesticidade privada?

- o que revela a expressão badanti?

- quais são as características da profissão, se é que se trata de uma profissão?

- que interpretação se pode dar sobre as notícias de jornais a respeito de incidentes que têm como protagonistas as badanti, as pessoas idosas e suas famílias?

- o que significa o fato de que todos os governos no poder, de direita ou de esquerda, tenham aberto isenções às leis de imigração para os trabalhadores que pertencem a essa categoria?

- quais poderão ser os efeitos sociais desse fenômeno migratório em longo prazo?

\section{Uma ótica antropológica}

Para tentar responder a essas questões, adotei a postura do observador participante, dentro da óptica da antropologia cultural comparativa. A escolha foi natural, já que exerci tanto a sociologia como a psicologia social na Itália e na França. O duplo pertencimento e a conexão entre os campos facilitariam por sua vez a reunião dos dados e o distanciamento necessário à análise. O "estupor" do observador externo me serviu para compreender o fenômeno "badanti" e me questionar sobre sua denominação.

Em comparação com a Itália, na França é recente a possibilidade de cruzarmos nas ruas com mulheres imigrantes acompanhando pessoas idosas. A profissão, na França, é conhecida como "ajuda domiciliar", cujo significado é diferente do de "badanti" e suas dimensões, em números, não são tão grandes como na Itália.

Para lidar com o envelhecimento da população, a França, que possui uma taxa de natalidade entre as mais elevadas da Europa, desenvolveu uma pluralidade de dispositivos de ajuda às pessoas idosas. Estes são articulados como público, privado e misto, o que faz a diferença em relação ao modelo que recorre aos recursos privados e familiares. ${ }^{5}$

Parece-me que, também graças à prevenção, a sociedade francesa tentou retardar o "long term care", facilitando o acesso de pessoas idosas a uma multiplicidade de opções que se

\footnotetext{
$4 \mathrm{O}$ trabalho das badanti começa a ser reconhecido como uma profissão pelo Contrato Nacional dos trabalhadores do comércio, com a organização de cursos profissionalizantes etc.

$5 \mathrm{Na}$ Franca, existem 10 mil residências para idosos, das quais 8 mil têm assistência médica. Entre estas, 40\% são públicas, 40\% são geridas por associações e $20 \%$ são particulares, com um objetivo lucrativo (entre as últimas, algumas, como Corion, são cotadas na bolsa de valores). As vagas disponíveis são $650 \mathrm{mil}$, das quais $550 \mathrm{mil}$ com acompanhamento médico. O setor emprega 350 mil pessoas e a arrecadação é de 18 bilhões de euros por ano. Os financiamentos provêm do sistema público de saúde ( 5,5 bilhões de euros por ano), das regiões, que contribuem com 1,5 bilhões de euros por ano para os problemas de idosos incapazes de se manter sozinhos, e de residentes que pagam cerca de 1.600 euros por mês (Secretariado do Estado). Na Itália, ao contrário, para cada 100 mil habitantes idosos de mais de 65 anos, 204 são acolhidos nas estruturas públicas. É um número muito pequeno, caso se preveja que, em 2016, o número de pessoas idosas de mais de 70 anos chegará a 9 milhões e meio; compreende-se assim porque as badanti foram muito favoravelmente acolhidas pelas famílias italianas (81\% dos cidadãos são favoráveis à regularização das trabalhadoras de fora da comunidade europeia) (IREF, 2007).
} 
combinam. Redes e medidas procuram promover a autonomia da pessoa e sua inscrição na coletividade.

Os municípios franceses, tal como no norte da Europa, estabeleceram uma rede de serviços para as pessoas, que vão das refeições a domicílio aos serviços domésticos e às compras. Esses serviços são modulados conforme as rendas, e, entre as facilidades criadas, existem os cheques-serviço, que foram introduzidos para tornar universal esse direito, assim como para fazer emergir o trabalho não declarado e clandestino. Além disso, experiências em formas de troca entre jovens e pessoas idosas, troca de serviços por moradia, ${ }^{6}$ estão em andamento em numerosas pequenas cidades universitárias (Tours, Aix etc.).

A presença de um Estado forte não é a única característica notável da França. Nos costumes franceses, permanecem os comportamentos ligados a uma mentalidade impregnada do espírito de serviço e da lógica de honra (Iribarne, 1989). Na tradição cultural francesa que forja as mentalidades, exercer um serviço, sobretudo no Estado e nas coletividades locais, não é desonroso, porque o valor do trabalho, a honra, estão ligados à qualidade oferecida e ao reconhecimento da coletividade. Assim como nas profissões, prêmios como do "primeiro operário da França" demostram essa mentalidade. Cada vez mais, o Estado, que é o fornecedor de serviços, é também o regulador, por meio da avaliação. A integração dos imigrantes foi facilitada pelos serviços recebidos e prestados. O conjunto dessas razões históricas é a origem do desenvolvimento dos serviços sociais, que hoje asseguram numerosos empregos qualificados. Além disso, o valor agregado desses serviços é aumentado, pois a França pode revender sua experiência adquirida aos outros países europeus.

Por outro lado, em vista da falta de uma responsabilização coletiva pelos serviços à pessoa, a escolha italiana de desenvolvimento socioeconômico favorece mais um "welfare" caseiro, que fica a cargo da família e não da coletividade. Hoje em dia, os serviços de cuidado às pessoas são delegados e externalizados, mas permanecem dentro do contexto familiar e doméstico. Trata-se de empregos diretos e empregos familiares, sem nenhuma mediação institucional (exceto o contrato nacional). A Itália não inova no domínio dos serviços; ela continua, em vez disso, a realizar uma outra forma de familismo.

\section{Sociedade arcaica, serviços arcaicos: as razões de uma escolha}

A propósito da integração dos imigrantes, Giuseppe De Rita, o mais ilustre dos sociólogos italianos não acadêmicos, comparava os diferentes modelos de integração do Reino Unido, da França e da Itália (De Rita, 2008). Sua tese é a seguinte: "Todo Estado integra os imigrantes através da exploração de seus recursos socioeconômicos dominantes, que são igualmente estruturas culturais". Na Itália, no interior do habitat das pequenas cidades é construída uma forma de integração inconsciente da população imigrante, graças à beleza das cidades onde o controle social é muito elevado. Outra forma de integração positiva passa pelo viés do trabalho. O imigrante internaliza o modelo italiano de "empresário autônomo", pequeno patrão de PME-PMI (pequena e média empresa, pequena e média indústria). Esse mimetismo social favorece a difusão de valores dos empresários: o grande número de pequenas empresas montadas pelos imigrantes é a prova disso. Neste caso específico, os imigrantes não apenas se integram, mas acrescentam um valor ao sistema local.

No caso das badanti, seguindo a linha de pensamento de De Rita, é evidente que esse novo serviço se inscreve também nas estruturas culturais italianas e, em particular, na esteira da velha tradição familista, onde o Estado está ausente. Por outro lado, eu me pergunto se o

6 A construção de prédios para pessoas idosas (residências com microapartamentos e serviços centralizados), que estava em moda nas décadas de 1980 e 1990, foi abandonada por causa dos custos fixos elevados, com os quais os residentes e seus familiares não podiam arcar. 
caráter próprio desse serviço ligado à domesticidade não é portador de efeitos perversos. A pergunta que me faço é a seguinte: é possível, hoje em dia, realizar uma boa integração das populações imigrantes só lhes oferecendo tarefas duras e de baixa qualificação, tarefas que, como dizemos habitualmente, "os italianos não têm mais vontade de assumir"? Procedendo dessa forma, não estaremos construindo uma sociedade na qual o valor do trabalho é cada vez mais hierarquizado, segundo uma escala que talvez não seja mais socialmente sustentável? Quais são as consequências para a sociedade da recusa, difundida transversalmente em todas as camadas sociais, em exercer certas profissões consideradas desvalorizantes? Que efeitos perversos se poderão desencadear?

O uso exclusivo dos serviços das badanti, mesmo preenchendo, hoje, uma necessidade e aparece como um recurso para a coletividade, impedindo a falência do sistema sanitário nacional, não poderia se revelar um grave erro em um futuro próximo? Erro que levaria a oportunidades perdidas, por não se ter repensado o pacto intergeracional numa sociedade em que as pessoas idosas são cada vez mais numerosas. Erro também por não terem sido criados, ao lado das badanti, novos serviços com maior valor agregado, capazes de engendrar empregados qualificados. Além disso, o fenômeno badanti poderá trazer pesadas consequências para o futuro próximo, com os sentimentos de frustração e de revanche que jorrarão nos imigrantes de segunda geração. Na verdade, em todo o país, se os imigrantes de primeira geração estão dispostos a aceitar qualquer tipo de trabalho, os da segunda geração reivindicam as mesmas oportunidades e a mesma ascensão social que os trabalhadores do país de acolhida.

\section{A denominação badanti: o significante}

Nomear é um ato performativo (Searle, 1982). O nome porta em si um significante importante e é também um indicador do valor atribuído ao sujeito. Nomear significa atribuir ao outro um status, uma posição social. Todavia, sendo a linguagem utilizada natural, aquele que nomeia raramente se questiona sobre o que diz.

O que quer dizer a denominação "badanti"? Eu não pude achar um sinônimo, uma palavra equivalente, nem em francês nem em inglês. Isso me alertou para o fato de que minha análise da profissão tinha como passagem obrigatória o desvelamento do termo. Em inglês, a palavra "care", "cuidar", é dialógica, tem uma conotação afetiva; em francês "auxiliaire de vie" liga ajuda e vida, e, na denominação "aide à domicile", a ajuda dialoga com domicílio. O termo italiano "badanti" vem do verbo "badare", que significa "vigiar", "proteger de perto". Trata-se de um verbo que é seguido por diferentes complementos, seja por objetos materiais, bens, seja por animais domésticos, seja por pessoas, na maioria das vezes crianças, que "inconscientemente", pela linguagem, são coisificadas. Expressões tais como "badare alla roba", "badare ai campi", "badare alle bestie", "badare ai bambini" e "badare ai vecchi" fazem parte da linguagem corrente e colocam em evidência o quanto o conceito de vigilância está estreitamente ligado ao de desconfiança, de desqualificação. Consequentemente, quando as pessoas utilizam esse falar às claras, elas desvalorizam de um só golpe badanti e badati, os dois membros do casal. Portanto, a palavra "badanti" é reveladora, pois desvenda uma realidade para a qual não temos coragem de olhar. Hoje, em nossa sociedade, as crianças e os idosos são relegados às margens, eles são as testemunhas de uma civilização rica em bens, mas deficiente em vínculos de afeto e de solidariedade.

7 “Cuidar dos bens", “cuidar dos campos”, “cuidar dos animais”, “cuidar das crianças”, “cuidar dos velhos". 


\section{Badante: uma condição de vida e de trabalho}

O trabalho da badante se caracteriza como um trabalho de "corpo a corpo", de "cara a cara" que engaja a subjetividade da trabalhadora. No cerne da profissão, existe a polivalência de tarefas e funções. A badante, que mora na casa, acompanha com seu corpo o corpo dos velhos e das crianças. Por ressonância, essa promiscuidade interroga os afetos e coloca em jogo toda a pessoa do trabalhador. As condições de base para exercer a profissão são o "equilíbrio emocional" e o sentimento de fazer parte de uma genealogia. Essas são as características que permitem a identificação positiva com o assistido. Além disso, elas contribuem para dar um sentido ao trabalho realizado. É por esse aspecto que a dureza da função pode assim ser aceita. Essas diferentes características são a base para se construírem as competências. A competência principal é a "discrição", "estar lá sem ali estar". Ela se desdobra sob a forma de respeito pelos outros, de capacidade de desviar o olhar quando o olhar pode invadir o espaço privado do outro e atingir sua dignidade.

O trabalho da badante, em geral uma mulher imigrante, é um trabalho muito árduo, tanto física como psiquicamente. Os afetos, provocados pelo cara a cara com o assistido, ocorrem sem mediações possíveis. De fato, para fazer baixar o estresse produzido pela pressão, a "distância" é necessária. Mas os papéis, cristalizados em sua assimetria, velho/ jovem, pobre/ rico, nacional/ imigrante e, sobretudo, o fato de que a atividade é exercida a portas fechadas, não tornam possível a distância apropriada. Os espaços privados são quase inexistentes, a badante dorme no domicílio do empregador e trabalha durante longas horas. Muito frequentemente, as badanti fazem julgamentos de valor negativos sobre comportamentos dos parentes do assistido, ${ }^{8}$ porque elas vêm de países onde os papéis sociais e sexuais permaneceram os mesmos de outrora, onde o respeito às pessoas idosas mantém seu valor e onde o sentido da dívida intergeracional é ainda muito forte. As avaliações que as badanti fazem sobre as famílias provavelmente tornam mais difícil sua tarefa e a identificação com a sociedade que as acolhe.

\section{Semelhanças e diferenças entre as profissões de serviços à pessoa}

Colf e badanti têm as mesmas condições de vida e de trabalho, a da domesticidade. Se, anteriormente, tratava-se de moças italianas que vinham das zonas rurais para as cidades para ajudar suas famílias e fazer seu enxoval, hoje, as domésticas - que, na linguagem politicamente correta, são denominadas colf (colaboradoras domésticas) - vêm de outros lugares, assim como as badanti. Elas são imigrantes vindas de países da Europa do Leste, da América do Sul, das Filipinas. Trabalham para famílias abastadas, sozinhas ou em casal, com seus maridos, com um contrato de trabalho do tipo privado que, em geral, é estipulado depois de um longo período de trabalho não declarado, realizado a título de reembolso da viagem efetuada do país de origem à Itália.

Essas figuras profissionais, presumidamente "pessoal de baixa qualificação", encontram as portas abertas e gozam de chamados privilegiados dentro do fluxo migratório. Para fazer frente ao envelhecimento da população e cuidar das crianças, outros países da área mediterrânea, como a Grécia e os países do sul, adotaram a mesma solução. Minha hipótese é que essa escolha está ligada ao status dado aos serviços e aos hábitos ligados às relações de servidão (Gorz, 1988).

Comparadas aos enfermeiros, outro tipo de profissão muito procurada no mercado de trabalho, vemos que estes se diferenciam das badanti e das colf, em razão de seu status superior,

8 Os italianos são criticados por suas relações com crianças e pessoas idosas na família. "Os italianos são pessoas de bem porque nos consideram parte da família, mas dentro de suas casas as crianças são mal-educadas e as pessoas idosas não são bem tratadas”. Essa é a opinião da maioria das 1003 colf e badanti entrevistadas pelo instituto IREF (IREF, 2007). 
porque seu trabalho é reconhecido como profissão. Suas condições de trabalho escapam à domesticidade, mesmo que elas compartilhem, embora em outro contexto, várias práticas técnicas com as badanti. ${ }^{9}$

É a análise das condições de vida e de trabalho que permite enxergar o que faz a diferença. $O$ perigo da desqualificação é também ligado à domesticidade. ${ }^{10}$ De fato, o quadro de trabalho dos enfermeiros é a instituição hospitalar. O trabalho é efetuado no interior de um "coletivo de trabalho" e responde a regras inscritas numa tradição codificada e numa estrutura de profissão. A distância necessária para respirar e aliviar o estresse engendrado pelo "cara a cara" é possível. Esse distanciamento existe graças à instituição, já que o Hospital permite a triangulação necessária e a mediação dos conflitos. Além disso, a instituição, com sua história, reconhece o sofrimento, a contribuição de uns e de outros, e facilita a construção do sentido do trabalho efetuado pelo conjunto dos trabalhadores.

Por outro lado, as badanti, mesmo quando fazem uma qualificação, são devolvidas à domesticidade e às relações ambíguas de familiaridade. ${ }^{11} \mathrm{Se}$, nos casos mais favoráveis, elas são os únicos remédios contra a solidão da pessoa idosa, permitindo que esta não caia em doenças crônicas, em muitos outros casos, a partir dessas relações ambíguas, ocorrem as mais atrozes violências, frequentemente recíprocas.

Não é por acaso que, nas notícias na imprensa italiana, aparecem crimes que têm como coprotagonistas badanti e badati. ${ }^{12}$ De fato, em todos os países do mundo, as taxas de crimes mais elevadas são aquelas referentes a crimes perpetrados entre pessoas próximas e dentro dos muros domésticos. Parece evidente que violência e domesticidade mantêm ligações muito fortes. É a condição de domesticidade que parece ser a base da violência latente que frequentemente se manifesta, gerando episódios dramáticos.

\section{Domesticidade e violência}

O retorno à sociedade de servidores prevista por André Gorz (1988) a respeito da metamorfose do trabalho atualiza o estudo magistral Les bonnes à tout faire [as empregadas que fazem tudo] de Louis Le Guillant (1984), que ilustra as relações entre domesticidade e violência. Com esse estudo, Le Guillant buscava compreender as causas subjacentes a uma notícia de jornal, o terrível delito perpetrado pelas irmãs Papin, domésticas que tinham matado sua patroa e cortaram seu corpo em pedaços. Procurava explicar as razões da porcentagem elevada de "bonnes à tout faire" entre os pacientes que permaneciam em seu hospital.

Le Guillant se questionava sobre as relações que poderiam existir entre a identidade de gênero, a profissão, as condições de trabalho e a etiologia dos indivíduos singulares. Ele não podia aceitar a hipótese corrente do déficit mental inato ou hereditário das pacientes, porque os sujeitos hospitalizados, jovens bretãs que estavam a serviço particular das famílias, tinham sido escolhidas entre as jovens mais audaciosas e espertas.

Cruzando as discussões clínicas e a leitura de obras literárias e filosóficas, Le Guillant derruba a imputação de tara genética e reconhece no clima de domesticidade e nas relações

\footnotetext{
9 Injeções, administração de remédios, primeiros socorros etc.

10 Há pouco tempo, a criação de cursos de formação especifica para tirar as badanti da desqualificação indica que esse tipo de serviço das badanti começa a ser reconhecido como profissão. Mas, dito isso, continuamos a negligenciar o reconhecimento das experiências de base das badanti, que não são de ordem técnica, mas moral, e esses cursos não mudam a visão da sociedade sobre o trabalho doméstico.

11 68\% das badanti comem com o assistido e 67\% assistem à televisão com ele na sala de estar.

12 Por exemplo: na cidade de Reggio Emilia, um aposentado de 88 anos matou com um tiro de fuzil sua badante romena de 44 anos, Eluta Ilaf (Corriere della Sera, outubro de 2008).
} 
ambíguas de familiaridade a origem principal do sofrimento no trabalho e o desencadeamento de ações criminosas.

Le Guillant retoma Hegel, na dialética senhor-escravo, citando, a título explicativo, extratos literários que revelam o fundamento da violência. É o contexto fechado que torna os conflitos explosivos, as paixões tristes. A convivência próxima com o outro derruba as barreiras. A familiaridade, combinada com a assimetria dos status, provoca conflitos intrapsíquicos que são vividos pelas trabalhadoras, que alternam momentos de amor e de ódio. Se adentrarmos o ambiente doméstico, podemos constatar o movimento crescente de mesquinharias que se encadeiam. Filmes célebres, que trabalharam com um realismo dramático o tema da domesticidade, ilustram bem o tema. ${ }^{13}$ É o "cara a cara", o conhecimento íntimo do outro, sua exposição, que desencadeiam os mecanismos da comparação social e produzem a inveja, o ressentimento, o desprezo. A vivência de humilhação é central em todos os relatos das trabalhadoras e, evidentemente, esse mal-estar subjetivo pode provocar maus tratos e/ou passagens ao ato.

\section{Contradições e paradoxos}

Entre as contradições que surgem na Itália, a que chama mais atenção é a guerra entre os nonni (avôs) e as badanti. O sindicato mais importante (CGIL) faz o papel de mediador, com seus quinhentos processos anuais, entre as trabalhadoras imigrantes e os aposentados, que, em razão da ausência de serviços sociais alternativos, foram coagidos a se tornar "patrões" das badanti. As pessoas idosas se queixam de terem sido abandonadas pelo seu sindicato e dizem: "essas mulheres nos maltratam, nós somos pobres e elas se aproveitam", ou então, "por que meu sindicato me considera um explorador? Eu dei a ela o que era justo" (Spezia, 2008). As reclamações colocam em evidência uma guerra entre pobres. ${ }^{14}$ De fato, em geral, com exceção de uma categoria abastada, o aposentado italiano, mesmo sendo proprietário de seu apartamento, não se assemelha a um grande burguês que recorret às badanti ou às colf para preservar seu bem-estar e seus hábitos de conforto. Os aposentados médios que recorrem a esse tipo de serviço frequentemente são pobres, sua aposentadoria é inferior ao salário devido à badante, e não encontram instituições capazes de lhes dar um suporte de vida, ou vivem em ambientes em que as pessoas estão muito ocupadas para cuidar deles.

A maior parte dos processos começa após a morte do assistido. O contrato termina e as badanti se dirigem ao sindicato para fazer valer seus direitos contra a família com quem tinham feito contrato, frequentemente "não declarado", enquanto elas ainda estavam em estado de clandestinidade. Por causa da ausência de práticas coletivas, de filtros e de mediações sociais, o conflito representa a última solução para os adversários, ou seja, a imigrante e a família do aposentado. Em geral, as controvérsias terminam por uma mediação junto ao sindicato e à Direção do Trabalho. Em razão das numerosas ambiguidades de parte a parte, e na ausência de provas concretas, porque tudo foi feito entre as paredes domésticas, em geral só são reconhecidas às badanti 50\% de suas pretensões.

Quem diz a verdade nesse espaço do indizível? Uma coisa é certa: outro espaço acaba de se abrir, facilitando o aumento do oportunismo social, essa nova forma de criminalidade predatória que caracteriza nossas sociedades pós-modernas.

\footnotetext{
13 Entre esses filmes, cito: Mulheres diabólicas, de Claude Chabrol (1995), Le domestique, de Jospeh Losey (1963), Vestígios do dia, de James Ivory (1993).

14 O montante mínimo de aposentadoria para idosos na Itália é de 602 euros, a média de aposentadorias INPS é 770 euros e apenas 10\% ultrapassam 1.500 euros. O salário de base mensal de uma badante é de 930 euros por treze meses por ano, sem contar as férias anuais e a indenização de fim de contrato (um mês de salário para cada ano de trabalho). Segundo uma pesquisa do sindicato FILCAMS-CGIL (FILCAMS-CGIL, 2011), o custo anual de uma badante fica em torno de 16.000 a 17.000 euros.
} 
No fundo, o problema reside na necessidade de redesenhar o sistema local de welfare, a fim de que as famílias não sejam mais abandonadas diante dessas situações penosas. É preciso também fazer o levantamento dos recursos necessários para sustentar as famílias que têm mais necessidade, ou que estão em maior dificuldade, seja porque elas recorrem às badanti, seja porque produzem, por si mesmas, medidas para a assistência.

\section{À guisa de conclusão}

A sociedade na qual vivemos é o resultado de nossas escolhas. Refletir sobre o fenômeno social constituído pelo recurso maciço ao serviço das badanti nos casos de cuidado com pessoas nos permite avançar para repensar o "welfare", a divisão de tarefas penosas entre os cidadãos.

Mudar a denominação badanti por outro termo politicamente mais correto não tem muito sentido. O que conta são os olhares que se cruzam, as representações sociais que forjam nossos valores. Badanti e badati nos interrogam, às margens da sociedade. E podemos questionálos como um sintoma para analisar nossa civilização. Para onde vamos? Que sociedade estamos construindo? Com quem?

A marginalização das badanti e das badati, e os enormes problemas que ela evidencia, nos pedem para inovar. A crise econômica e social em curso poderia ser uma ocasião, um fator para progredir de outra forma, para repensar as escolhas e parar de fazer sempre a mesma coisa.

Todavia, será cada vez mais difícil realizar esses objetivos, porque as condições econômicas estão mais difíceis após as decisões tomadas pelo governo tecnocrata que ocupa o poder na Itália desde o fim de 2011. Para alcançar rapidamente um resultado favorável, esse governo aumentou os impostos sobre os imóveis, em nível quase insustentável para uma grande parcela da população. As famílias, e, em particular, os aposentados, tomados pelo medo, encontram-se em graves dificuldades financeiras e deixaram de consumir. Consequentemente, a demanda de serviços foi reduzida. Os trabalhadores imigrantes, em particular os colf, também são vítimas da dívida do estado. ${ }^{15}$

Se esta reflexão partiu de um questionamento sobre as badanti e sobre os serviços à pessoa, em geral, esses serviços essenciais, que determinam o nível de civilização e de bem-estar de uma sociedade, ela prossegue idealmente com outras questões sobre as significações que englobam o termo "care". Minha intenção é levantar um debate maior para repensar o "welfare", reformá-lo para salvaguardar suas conquistas, tornando-o sustentável. Manter os serviços às pessoas idosas é uma escolha de sociedade que não concerne apenas aos servidores sociais, visto que se trata de um setor que tem uma dimensão política, ética e social.

\section{Referências}

Bonnet, M. (2008). Relation d'aide et aide en gérontologie. Nouvelle Revue de Psychosociologie, 6, 108-121.

Cazzullo, A. (2010). L'amore al tempo delle moldave. Corriere della Sera, 24 maio 2010.

FILCAMS-CGIL. (2011). Colf, le famiglie spendono 26 miliardi l’anno. Recuperado em 15 de abril, 2011, de www.filcams.cgil.it.

Gorz, A. (1988). Métamorphoses du travail. Paris: Galilée.

IREF de ACLI (Institut de Recherche et Formation de l'Action Catholique des Travailleurs Italiens) (2007). Il welfare fatto in casa. Relatório de pesquisa. 
Iribarne, P. (1989). La logique de l'honneur. Gestion des entreprises et traditions nationales. Paris: Seuil.

Le Guillant, L. (1984). Les bonnes à tout faire. Toulouse: Érès.

Marcucci De vincenti, A. (2009). Le badanti: un nuovo mestiere? La Critica Sociologica, 171 (43), 91-98.

Molinier, P. , Laugier, S. \& Paperman, P. (Orgs.) (2010). Qu'est-ce que le care? Souci des autres, sensibilité, responsabilité. Paris: Payot.

Putnam, R., Leonardi, R. \& Nannetti, R. (1993). Making democracy work: civic traditions in modern Italy. Princeton: University Press.

Rita, G. (2008). Troppe tentazioni. Corriere della Sera, 6 out 2008.

Searle, J. (1982). Sens et expression. Etudes de théorie des actes de langage. Paris: Éditions de Minuit.

Spano, P. (2006). Badanti: funzioni domestiche e infermiere si sovrappongono. Milão: Università Bocconi. Relatório de pesquisa.

Spezia, L. (2008). Nonni-badanti separati in CGIL. Recuperado em 14 de abril, 2009, de www.repubblica.it.

Stella, G. A. (2008). Il buon senso delle badanti. Corriere della Sera, 17 maio 2008.

\section{Endereço para correspondência} antonelladevincenti@gmail.com 